\title{
Screen time duration and timing: effects on obesity, physical activity, dry eyes, and learning ability in elementary school children
}

Yui Mineshita ${ }^{1 \dagger}$, Hyeon-Ki Kim ${ }^{1 \dagger}$, Hanako Chijiki ${ }^{2}$, Takuya Nanba², Takae Shinto², Shota Furuhashi ${ }^{2}$, Satoshi Oneda ${ }^{2}$, Mai Kuwahara', Anzu Suwama' and Shigenobu Shibata ${ }^{1,2^{*}}$

\begin{abstract}
Background: As internet use becomes more widespread, the screen time (ST) of elementary school students increases yearly. It is known that longer durations of ST can affect obesity, physical activity, dry eye disease, and learning ability. However, the effects of ST just before bedtime have not been clarified. Therefore, we examined ST duration and timing effects on elementary school children.

Methods: We conducted a survey of 7419 elementary school students in Tokyo, Japan using a questionnaire on food education. ST duration and timing (just before bedtime) served as the explanatory variables, and the relationship between obesity, physical activity, dry eyes, and learning ability was analyzed using logistic regression analysis. Gender, school year, height, and weight were considered confounding factors. First, we examined whether ST duration and timing were related to each objective variable, using a univariate model to examine all variables. Thereafter, we performed multivariate logistic regression analyses for all variables showing a significant difference in the univariate models.

Results: A significant association was observed between ST duration and obesity, physical activity, and academic performance, indicating that a longer ST duration may lead to obesity, decreased physical activity, and decreased academic performance. ST timing was associated with obesity, dry eyes, and academic performance, and ST immediately before bedtime contributed to obesity, dry eyes, and reduced academic performance. Furthermore, the results of investigating the combined effect of ST duration and timing (immediately before bedtime) on these factors revealed that ST timing has a greater effect on dry eyes, and ST duration has a greater effect on academic performance.
\end{abstract}

Conclusion: Our findings indicate that ST in school children is related to obesity, physical activity, dry eyes, and learning ability, and they suggest that not only the duration but also the timing of ST is important.

Keywords: Screen time, Elementary school students, Obesity, Physical activity, Dry eyes, Learning ability

\footnotetext{
*Correspondence: shibatas@waseda.jp

${ }^{\dagger}$ Yui Mineshita and Hyeon-ki Kim contributed equally to this work.

'Laboratory of Physiology and Pharmacology, School of Advanced Science

and Engineering, Waseda University, 2-2 Wakamatsu-cho Shinjuku, Tokyo

162-0056, Japan

${ }^{2}$ Graduate School of Advanced Science and Engineering, Waseda University,

2-2 Wakamatsu-cho Shinjuku, Tokyo 162-0056, Japan
}

(c) The Author(s). 2021 Open Access This article is licensed under a Creative Commons Attribution 4.0 International License, which permits use, sharing, adaptation, distribution and reproduction in any medium or format, as long as you give appropriate credit to the original author(s) and the source, provide a link to the Creative Commons licence, and indicate if changes were made. The images or other third party material in this article are included in the article's Creative Commons licence, unless indicated otherwise in a credit line to the material. If material is not included in the article's Creative Commons licence and your intended use is not permitted by statutory regulation or exceeds the permitted use, you will need to obtain permission directly from the copyright holder. To view a copy of this licence, visit http://creativecommons.org/licenses/by/4.0/. The Creative Commons Public Domain Dedication waiver (http://creativecommons.org/publicdomain/zero/1.0/) applies to the data made available in this article, unless otherwise stated in a credit line to the data. 


\section{Background}

The increasing levels of internet access indicates steadily increasing usage time (screen time or ST) of digital devices such as TVs, smartphones, tablets, and gaming consoles increases year after year. According to data from a survey of elementary school students conducted by the Mobile Marketing Data Laboratory, $40.1 \%$ of students began using smartphones in 2019 [1]. In addition, data from the Cabinet Office of Japan indicate that in 2018 , the internet usage rate exceeded $85 \%$ for elementary school students, and the average internet usage time increased by approximately $21 \mathrm{~min}$ compared to that in the previous year [2]. These data suggest that children are going online at younger ages and that elementary school students' ST is increasing.

The various effects of longer ST duration on children's health and life events are widely known. In the physical activity guidelines for children, ST is positively associated with sedentary behavior, therefore it is recommended to be limited to $2 \mathrm{~h}$ a day [3]. The World Health Organization (WHO) recommends that children and adolescents (5-17 years of age) perform at least 60 min of moderate to vigorous physical activity per day [4]. Nevertheless, in Japan, it was found that approximately $60 \%$ of children exceeded the two-hour-per-day maximum of sedentary behavior [5], and approximately half of the Japanese elementary school students did not achieve the recommended physical activity levels [6]. Lower levels of physical activity and longer sedentary periods from longer ST duration can increase the risk of obesity. Additionally, recent studies have demonstrated the potential effects of sedentary behavior and physical activity on academic performance $[3,7,8]$, and that long periods of focused ST may lead to incomplete eye blinking and therefore, may result in dry eyes [9-11]. However, few studies have examined the relationship between ST and dry eye disease in children.

Along with the duration of the ST, the time of ST occurrence (e.g., just before bedtime) is also an important factor in ST-induced decreased physical activity, academic performance, and the increased frequency of dry eye disease. Visible light affects the central biological clock in the suprachiasmatic nucleus of the hypothalamus in the human brain, with morning light exposure advancing this biological clock and late-night light exposure (including light from LED devices) delaying it [12]. In addition, nighttime light exposure suppresses the secretion of melatonin, a sleep-promoting hormone, from the pineal gland [13-15]. This can interfere with sleep onset [13-15]. Thus, ST just before bedtime can be problematic.

This body of evidence suggests that not only the duration of ST but also ST before bedtime may affect obesity, physical activity, academic performance, and dry eyes in children. Therefore, in the current study, we examined the combined effects of ST duration and timing (just before bedtime) on these factors in elementary school children. To our knowledge, no study has examined multiple factors as objective variables for ST duration and timing in the same group of elementary school students. In this study, we aim to determine not only the influence of ST duration but also the novel combined effect from ST duration and timing.

\section{Methods \\ Participants and the super diet education (Shokuiku) project}

The Super Diet Education (Shokuiku) Project was a food education project supported by the Japanese Ministry of Education, Culture, Science and Technology. It was designed to develop programs to promote children's dietary education in collaboration with various external organizations. The project's overall aim was to contribute to a healthy lifestyle in school children and improve their health through nutrition education. In Japanese, "shoku" means diet, and "iku" means growth and education. In this project, a cross-sectional study was conducted on a cohort of elementary school children using a survey questionnaire. In total, 7419 children (612 years of age) from 18 elementary schools in Minato City, Japan participated in the survey during 2018-2019. Cases with missing data were excluded from the analysis. The study was approved by the Ethics Review Committee on Research with Human Subjects of Waseda University (application no. 2019-195).

\section{Questionnaire}

Teachers at the schools explained the purpose of the study and distributed the questionnaires, and then children and their parents completed the questionnaires and returned them to the schools. Via the questionnaires, information was collected on gender, school year (1 to 6), learning ability, physical activity, ST duration and timing, and anthropometrics. Table 1 presents a summary of the question contents and response options. An additional file shows this in more detail [see Additional file 1].

\section{Obesity}

The obesity variables consisted of the BMI percentiles and Rohrer index scores, which were assessed using selfreported height and weight. In 1997, the WHO and the International Obesity Task Force adopted BMI as a valid criterion for determining childhood obesity [16]. However, growth can affect BMI; therefore, it cannot be used in the same way in children as it can be in adults. As BMI tends to change considerably with age [17], the BMI percentiles were classified into two groups using 
Table 1 Question contents and response options for the explanatory variables and objective variables

\begin{tabular}{|c|c|c|}
\hline & Explanatory variable & Content of question \\
\hline \multirow[t]{5}{*}{ Screen time } & Duration & $\begin{array}{l}\text { How much time do you spend per day playing on smartphones or computers, } \\
\text { using communication applications, playing video games, or watching TV or videos? }\end{array}$ \\
\hline & & 1. $>5 \mathrm{~h} ; 2.3 \mathrm{~h}$ to $<5 \mathrm{~h} ; 3.1 \mathrm{~h}$ to $<3 \mathrm{~h} ; 4 .<1 \mathrm{~h}$ \\
\hline & Timing & $\begin{array}{l}\text { Just before you sleep, do you play on smartphones or computers, use communication } \\
\text { applications, play video games, or watch TV or videos? }\end{array}$ \\
\hline & & 1. Often; 2. Sometimes; 3. Rarely; 4. Never \\
\hline & Objective variable & \\
\hline \multirow[t]{2}{*}{ Obesity } & BMI percentiles & Calculated using height and weight \\
\hline & Rohrer index & Calculated using height and weight \\
\hline \multirow[t]{2}{*}{ Physical activity } & Weekly physical activity & $\begin{array}{l}\text { In the last } 7 \text { days, how many days have you engaged in physical activities for more } \\
\text { than } 60 \text { min? }\end{array}$ \\
\hline & & 1. 0 days; 2.1 day; 3.2 days; 4.3 days; 5.4 days; 6.5 days; 7.6 days; 8.7 days \\
\hline \multirow[t]{2}{*}{ Dry eyes } & Dry eyes & Do you have dry eyes? \\
\hline & & 1. Often; 2. Sometimes; 3. Rarely; 4. Never \\
\hline \multirow[t]{4}{*}{ Learning ability } & Class & Do you understand the material presented in your classes at school? \\
\hline & & 1. understand; 2 . mostly understand; 3 . slightly understand; 4. never understand \\
\hline & Performance & Please describe your performance in classes at school (presentation, tests, etc.) \\
\hline & & $\begin{array}{l}\text { 1. perform very well; } 2 \text {. perform in a satisfactory manner; } 3 \text {. do not perform well; } 4 \text {. } \\
\text { cannot perform at all }\end{array}$ \\
\hline
\end{tabular}

age- and gender-appropriate charts [18] according to the following guidelines from Japan's Ministry of Health, Labour and Welfare: "normal "(BMI $\leq 5$ th but $<85$ th percentile) and "obese" (BMI $\geq 85$ th percentile). The Rohrer indexes were also divided into two groups: the "obese" group, with children who had Rohrer indices $\geq 145$, and the "normal" group, with those who had Rohrer indices between 115 and 145. The Rohrer index score was calculated as shown below [19].

$$
\text { Rohrer index }=\text { weight }(\mathrm{kg}) / \text { height }(\mathrm{cm})^{3} \times 10^{7}
$$

\section{Physical activity}

Large-scale population surveys, using a self-report questionnaire are the most feasible method for measuring physical activity $[20,21]$. The WHO Health Behaviour in School-Aged Children (HBSC) survey is one of the most comprehensive sources of data on school-aged students' physical activity levels [22]. The HBSC has been translated into Japanese (HBSC-J), and it has been shown to be valid [23]. In our questionnaire, we used the following item from the HBSC to assess how often participants engaged in moderate-to-vigorous physical exercise: "In the last 7 days, how many days have you engaged in physical activities for more than 60 minutes?" The responses to this question were categorized as follows: 1 for 0 days; 2 for 1 day; 3 for 2 days; 4 for 3 days; 5 for 4 days; 6 for 5 days; 7 for 6 days; and 8 for 7 days. The responses for weekly physical activities were divided into two groups: the "high physical activities" group with children who were above the median and the "low physical activities" group, with those who were below it.

\section{Dry eyes}

The Dry Eye-Related Quality-of-Life Score (DEQS) questionnaire was created and validated in Japan [24]. We created the questionnaire items to assess dry eye symptoms based on the DEQS questionnaire. We asked the participants, "Do you have dry eyes?" The responses were on a scale from 1 to 4: 1, often; 2, sometimes; 3, rarely; and 4, never. "Dry eyes" responses were also divided into two groups: the "dry" group, with children who answered 1 or 2, and the "not dry" group, with those who answered 3 or 4 .

\section{Learning ability}

The study group consisted of "class," and "performance," which were divided into two groups. We asked the participants, "Do you understand the material presented in your classes at school?" The answers for "class" were categorized from 1 to 4: 1, understand; 2, mostly understand; 3, slightly understand; and 4, never understand. "Class" answers were then divided into two groups: the "understand" group, with children who answered 1 or 2 , and the "do not understand" group, with those who answered 3 or 4 . The questions used in this item were also used in a previous study [25]. In addition, we asked the participants, "Please describe your performance at school (in classes, on tests, etc.)." The answers for 
"performance" were categorized from 1 to 4: 1, perform very well; 2 , perform in a satisfactory manner; 3 , do not perform well; and 4, cannot perform at all. "Performance" answers were then divided into two groups: the "good" group, with children who answered 1 or 2, and the "poor" group, with those who answered 3 or 4 . In Japan, where researchers' access to children's actual academic data is restricted, subjective learning ability is used as a feasible surrogate variable [26, 27]. Selfreported grades and actual grades have previously been reported to be generally accurate [28].

\section{ST duration and timing}

Two items, the duration and timing of ST, were used as indicators of ST. We asked the participants, "How much time do you spend per day playing on smartphones or computers, using communication applications, playing video games, or watching TV or videos?" The responses for "duration of ST" were on a scale from 1 to $4: 1$ to indicate $\geq 5 \mathrm{~h} ; 2$ to indicate $3 \mathrm{~h}$ to $<5 \mathrm{~h} ; 3$ to indicate $1 \mathrm{~h}$ to $<3 \overline{\mathrm{h}} \overline{\overline{\text { }}}$ and 4 to indicate $<1 \mathrm{~h}$. The "duration of ST" responses were then divided into three groups: the "above 3 hours" group, with children who answered 1 or 2; the "1-3 h" group, with those who answered 3; and the "less than 1 hour" group, with those who answered 4. The current American Academy of Pediatrics guidelines recommend that children under 2 years of age should not spend any time using electronic media, while the ST of children over 2 years of age should be kept to less than $2 \mathrm{~h}$ per day $[29,30]$. Therefore, $2 \mathrm{~h}$ is often used as a reference for ST. However, Minato City is implementing the "Minato-ku School Informatization Action Plan" and has been introducing electronic teaching materials in classes [31]. As a result, ST among Minato City elementary school students is increasing. Considering that headaches and sleep difficulties have been reported as after more than $3 \mathrm{~h}$ of ST [32], we used $3 \mathrm{~h}$ as the ST reference, which is $1 \mathrm{~h}$ more than the American Academy of Pediatrics guidelines. We asked the participants, "Just before you sleep, do you play on smartphones or computers, use communication applications, play video games, or watch TV or videos?" The responses for "timing of ST" were on a scale from 1 to $4: 1$, often; 2 , sometimes; 3, rarely; and 4, never. The "timing of ST" responses were then divided into two groups: the "yes" group, with children who answered 1 or 2 , and the "no" group, with those who answered 3 or 4 . Next, in order to examine differences in the influences of ST duration and timing, we used a combination of ST duration and timing as the explanatory variable (Table 2). For each objective variable, a logistic regression analysis comparing G1 and G2, G3 and G4, and G5 and G6 was performed.
Table 2 The combination of ST duration and timing

\begin{tabular}{|c|c|c|c|c|c|}
\hline \multirow[t]{2}{*}{ Group } & \multicolumn{3}{|c|}{ ST duration } & \multicolumn{2}{|c|}{ ST timing } \\
\hline & $\begin{array}{l}\text { Above } \\
3 \mathrm{~h}\end{array}$ & $1-3 h$ & $\begin{array}{l}\text { Less than } \\
1 \mathrm{~h}\end{array}$ & Yes & No \\
\hline$\overline{\mathrm{G} 1}$ & $\mathrm{O}$ & & & $\mathrm{O}$ & \\
\hline G2 & O & & & & $\mathrm{O}$ \\
\hline G3 & & $\mathrm{O}$ & & $\mathrm{O}$ & \\
\hline G4 & & O & & & $\mathrm{O}$ \\
\hline G5 & & & $\mathrm{O}$ & $\mathrm{O}$ & \\
\hline G6 & & & $\mathrm{O}$ & & $\mathrm{O}$ \\
\hline
\end{tabular}

\section{Statistical analyses}

A chi-square test was performed to compare the sex and school year used as confounding factors by groups. The Wilcoxon test was used to compare height and weight by groups. The objective variables used in this study were as follows: "body mass index (BMI) percentiles" and the "Rohrer index" (for obesity), "weekly physical activities," "dry eyes," "class," and "performance." The explanatory variables were "duration of ST" and "timing of ST." The ST in each group was examined using logistic regression analysis. First, we examined whether ST duration and timing were related to each objective variable. All variables were examined using a univariate model. Afterward, we performed multivariate logistic regression analyses for all variables that showed a significant difference in the univariate models. The odds ratios (ORs) and 95\% confidence intervals (CIs) were calculated. The sample size was calculated to detect a medium effect $\left[f^{2}\right.$ (effect size $\left.)=0.15\right]$. A minimum sample size of 146 was required to have approximately $95 \%$ power to detect large effects at a significant level of 0.05 (G*Power, version 3.1.9.2, Universitat Kiel, Germany). All data were analyzed using predictive analytics software for Windows (Statistical Package for the Social Sciences; IBM Corp., Chicago, IL, USA); a $p$ value of $<0.05$ indicated statistical significance.

\section{Results}

The characteristics of the "obese," "physical activity," "dry eyes," and "learning ability" groups are presented in Tables 3, 4, 5 and 6 . An analysis of the results of a questionnaire in which 6334 (85.38\%) and $4683(63.12 \%)$ of school children answered all items related to "BMI percentiles" and "Rohrer index", respectively, was performed (Table 3). There were significant differences in gender and school year between the "normal" and "obese" groups. For the "weekly physical activities", "dry eyes", "class", and "performance" items, 7048 (95.00\%), 7041 (94.90\%), 7026 (94.70\%), and 7071 (95.31\%) elementary school children, respectively, answered all questionnaire items and an analysis of the results was conducted (Tables 4, 5 and 6). There were significant differences in 
Table $\mathbf{3}$ Characteristics of the children in the obese group

\begin{tabular}{|c|c|c|c|c|c|c|c|c|c|c|c|c|c|}
\hline \multirow{3}{*}{\multicolumn{2}{|c|}{$\begin{array}{l}\text { Item } \\
\text { Age, mean (SE) }\end{array}$}} & \multicolumn{6}{|c|}{ BMI percentiles } & \multicolumn{6}{|c|}{ Rohrer index } \\
\hline & & \multirow[b]{3}{*}{$\mathbf{N}$} & \multicolumn{2}{|c|}{ Normal } & \multicolumn{2}{|c|}{ Obese } & \multirow[b]{3}{*}{$P$-value ${ }^{a}$} & \multirow[b]{3}{*}{$\mathbf{N}$} & \multicolumn{2}{|c|}{ Normal } & \multicolumn{2}{|c|}{ Obese } & \multirow[b]{3}{*}{$P$-value ${ }^{a}$} \\
\hline & & & 9.04 & $(0.023)$ & 9.21 & $(0.063)$ & & & 8.76 & $(0.023)$ & 8.99 & $(0.069)$ & \\
\hline & & & $\mathrm{n}$ & $\%$ & $\mathbf{N}$ & $\%$ & & & $\mathbf{N}$ & $\%$ & $\mathrm{~N}$ & $\%$ & \\
\hline \multirow[t]{2}{*}{ Gender } & Boys & 3346 & 2882 & 86.1 & 464 & 13.9 & $<0.001$ & 2582 & 2160 & 83.7 & 422 & 16.3 & $<0.001$ \\
\hline & Girls & 2988 & 2744 & 91.8 & 244 & 8.2 & & 2101 & 1886 & 89.8 & 215 & 10.2 & \\
\hline \multirow[t]{6}{*}{ School year } & 1 & 1235 & 1126 & 91.2 & 109 & 8.8 & 0.021 & 1136 & 996 & 87.7 & 140 & 12.3 & 0.021 \\
\hline & 2 & 1161 & 1039 & 89.5 & 122 & 10.5 & & 945 & 833 & 88.1 & 112 & 11.9 & \\
\hline & 3 & 1106 & 978 & 88.4 & 128 & 11.6 & & 813 & 708 & 87.1 & 105 & 12.9 & \\
\hline & 4 & 1080 & 949 & 87.9 & 131 & 12.1 & & 730 & 626 & 85.8 & 104 & 14.2 & \\
\hline & 5 & 989 & 857 & 86.7 & 132 & 13.3 & & 617 & 511 & 82.8 & 106 & 17.2 & \\
\hline & 6 & 763 & 677 & 88.7 & 86 & 11.3 & & 442 & 372 & 84.2 & 70 & 15.8 & \\
\hline
\end{tabular}

${ }^{\mathrm{a} C h i-s q u a r e ~ t e s t}$

gender, school year, height, and weight between the "weekly physical activities" and "dry eyes" groups. Additionally, for the "performance", between the "good" and "poor" groups, there were significant differences in gender, school year, and weight; however, there was no significant difference in height. For "class", between the "understand" and "do not understand" groups, there were significant differences in gender, school year, and height; however, there was no significant difference in weight.

The results of the multivariate analysis for each objective variable are presented in Table 7 . The duration $(1 \mathrm{~h}$ to $<3 \mathrm{~h}: \mathrm{OR}=0.61,95 \% \mathrm{CI}=0.50-0.74 ;<1 \mathrm{~h}: \mathrm{OR}=0.42$, $95 \% \mathrm{CI}=0.33-0.54)$ and timing of ST $(\mathrm{OR}=0.78,95 \%$ CI $0.65-0.93)$ were positively correlated with the "BMI

Table $\mathbf{4}$ Characteristics of the children in the physical activity group

\begin{tabular}{|c|c|c|c|c|c|c|c|}
\hline \multirow[b]{2}{*}{ Item } & & \multicolumn{6}{|c|}{ Weekly physical activities ${ }^{c}$} \\
\hline & & & \multicolumn{2}{|l|}{ High } & \multicolumn{3}{|l|}{ Low } \\
\hline & & & Mean & SE & mean & SE & $P$-value \\
\hline Age & & & 8.95 & 0.027 & 9.2 & 0.031 & \\
\hline Height & & & 134.0 & 0.18 & 135.2 & 0.21 & $<0.001$ \\
\hline \multirow[t]{2}{*}{ Weight } & & & 29.9 & 0.13 & 31.2 & 0.16 & $<0.001$ \\
\hline & & N & N & $\%$ & $\mathrm{n}$ & $\%$ & $P$-value \\
\hline \multirow[t]{2}{*}{ Gender } & Boys & 3619 & 2161 & 59.7 & 1458 & 40.3 & $<0.001$ \\
\hline & Girls & 3429 & 1605 & 46.8 & 1824 & 53.2 & \\
\hline \multirow[t]{6}{*}{ School year } & 1 & 1393 & 756 & 54.3 & 637 & 45.7 & $<0.001$ \\
\hline & 2 & 1283 & 723 & 56.4 & 560 & 43.6 & \\
\hline & 3 & 1218 & 705 & 57.9 & 513 & 42.1 & \\
\hline & 4 & 1180 & 670 & 56.8 & 510 & 43.2 & \\
\hline & 5 & 1111 & 560 & 50.4 & 551 & 49.6 & \\
\hline & 6 & 863 & 352 & 40.8 & 511 & 59.2 & \\
\hline
\end{tabular}

${ }^{\mathrm{a}}$ Wilcoxon. ${ }^{\mathrm{b}} \mathrm{Chi}$-square test

${ }^{\mathrm{C}}$ The median number of physical activities per week was divided into two percentiles." These results show that the participants with shorter ST durations per day were more likely to be in the "normal" group. In addition, the results show that those who did not have ST before bedtime were more likely to be in the "normal" group than those who did. The duration $(1 \mathrm{~h}$ to $<3 \mathrm{~h}$ : $\mathrm{OR}=0.65,95 \% \mathrm{CI}=0.52-$ $0.81 ;<1 \mathrm{~h}: \mathrm{OR}=0.43,95 \% \mathrm{CI}=0.32-0.57)$ and timing of ST $(\mathrm{OR}=0.73,95 \% \mathrm{CI}=0.60-0.90)$ were positively correlated with the "Rohrer index" item. These results show that the participants with shorter ST durations per day were more likely to be in the "normal" group. In addition, the results show that those who did not have ST before bedtime were more likely to be in the "normal" group.

The duration of ST $(1 \mathrm{~h}$ to $<3 \mathrm{~h}: \mathrm{OR}=1.19,95 \% \mathrm{CI}=$ $1.03-1.37 ;<1 \mathrm{~h}: \mathrm{OR}=1.27,95 \% \mathrm{CI}=1.08-1.48)$ was negatively correlated with the "weekly physical activities"

Table 5 Characteristics of children with dry eyes

\begin{tabular}{|c|c|c|c|c|c|c|c|}
\hline \multirow{3}{*}{ Item } & & \multicolumn{6}{|c|}{ Dry eyes } \\
\hline & & & \multicolumn{2}{|c|}{ Not dry } & \multicolumn{3}{|l|}{ Dry } \\
\hline & & & mean & SE & mean & SE & $P$-value ${ }^{a}$ \\
\hline Age & & & 8.98 & 0.023 & 9.44 & 0.048 & \\
\hline Height & & & 134.1 & 0.16 & 136.8 & 0.32 & $<0.001$ \\
\hline \multirow[t]{2}{*}{ Weight } & & & 30.1 & 0.11 & 31.9 & 0.24 & $<0.001$ \\
\hline & & $\mathrm{N}$ & $\mathrm{n}$ & $\%$ & $\mathrm{~N}$ & $\%$ & $P$-value ${ }^{b}$ \\
\hline \multirow[t]{2}{*}{ Gender } & Boys & 3611 & 2921 & 80.9 & 690 & 19.1 & 0.25 \\
\hline & Girls & 3430 & 2811 & 82.0 & 619 & 18.0 & \\
\hline \multirow[t]{6}{*}{ School year } & 1 & 1385 & 1208 & 87.2 & 177 & 12.8 & $<0.001$ \\
\hline & 2 & 1280 & 1073 & 83.8 & 207 & 16.2 & \\
\hline & 3 & 1219 & 1007 & 82.6 & 212 & 17.4 & \\
\hline & 4 & 1179 & 934 & 79.2 & 245 & 20.8 & \\
\hline & 5 & 1114 & 870 & 78.1 & 244 & 21.9 & \\
\hline & 6 & 864 & 640 & 74.1 & 224 & 25.9 & \\
\hline
\end{tabular}

${ }^{a}$ Wilcoxon. ${ }^{b}$ Chi-square test 
Table 6 Characteristics of the children in learning ability group

\begin{tabular}{|c|c|c|c|c|c|c|c|c|c|c|c|c|c|}
\hline \multirow{3}{*}{ Item } & & \multicolumn{6}{|l|}{ Class } & \multicolumn{6}{|c|}{ Performance } \\
\hline & & & \multicolumn{2}{|c|}{ Understand } & \multicolumn{2}{|c|}{ Do not understand } & \multirow[b]{2}{*}{$P$-value ${ }^{a}$} & & \multicolumn{2}{|l|}{ Good } & \multicolumn{3}{|l|}{ Poor } \\
\hline & & & mean & SE & mean & SE & & & mean & SE & Mean & SE & $P$-value ${ }^{\mathrm{a}}$ \\
\hline Age & & & 9.08 & 0.021 & 8.71 & 0.103 & & & 9.03 & 0.022 & 9.26 & 0.053 & \\
\hline Height & & & 134.7 & 0.14 & 132.3 & 0.72 & $<0.001$ & & 134.5 & 0.15 & 135.1 & 0.37 & 0.090 \\
\hline \multirow[t]{2}{*}{ Weight } & & & 30.5 & 0.10 & 30.5 & 0.59 & 0.089 & & 30.2 & 0.11 & 31.7 & 0.29 & $<0.001$ \\
\hline & & N & $\mathrm{n}$ & $\%$ & N & $\%$ & $P$-value ${ }^{b}$ & N & $n$ & $\%$ & N & $\%$ & $P$-value \\
\hline \multirow[t]{2}{*}{ Gender } & Boys & 3594 & 3414 & 95.0 & 180 & 5.0 & 0.009 & 3623 & 2962 & 81.8 & 601 & 16.6 & 0.001 \\
\hline & Girls & 3432 & 3304 & 96.3 & 128 & 3.7 & & 3438 & 3022 & 87.9 & 476 & 13.8 & \\
\hline \multirow[t]{6}{*}{ School year } & 1 & 1389 & 1305 & 94.0 & 84 & 6.0 & 0.017 & 1394 & 1226 & 87.9 & 168 & 12.1 & $<0.001$ \\
\hline & 2 & 1273 & 1213 & 95.3 & 60 & 4.7 & & 1288 & 1109 & 86.1 & 179 & 13.9 & \\
\hline & 3 & 1218 & 1171 & 96.1 & 48 & 3.9 & & 1223 & 1052 & 86.0 & 171 & 14.0 & \\
\hline & 4 & 1174 & 1132 & 96.4 & 42 & 3.6 & & 1182 & 976 & 82.6 & 206 & 17.4 & \\
\hline & 5 & 1114 & 1070 & 96.1 & 44 & 3.9 & & 1113 & 909 & 81.7 & 204 & 18.3 & \\
\hline & 6 & 858 & 827 & 96.4 & 31 & 3.6 & & 861 & 712 & 82.7 & 149 & 17.3 & \\
\hline
\end{tabular}

ailcoxon

${ }^{\mathrm{b}}$ Chi-square test

item, while ST timing was not. These results show that the participants with shorter durations of ST per day participated in more physical activities.

The ST timing $(\mathrm{OR}=1.31,95 \% \mathrm{CI}=1.15-1.50)$ was negatively correlated with the "dry eyes" item, while ST duration was not. These results show that students who did not have ST just before bedtime were less likely to have dry eyes compared to those who did.

The duration $(1 \mathrm{~h}$ to $<3 \mathrm{~h}$ : $\mathrm{OR}=2.24,95 \% \mathrm{CI}=1.71-$ $2.94 ;<1 \mathrm{~h}: \mathrm{OR}=3.93,95 \% \mathrm{CI}=2.70-5.71)$ and timing of ST $(\mathrm{OR}=1.43,95 \% \mathrm{CI}=1.10-1.86)$ were associated with the "class" item. These results show that the participants with shorter ST durations per day had a better understanding of the material presented in their classes. In addition, results show that those who did not have ST before bedtime were more likely to understand the material presented in their classes than those who did. For the "performance" item, the duration $(1 \mathrm{~h}$ to $<3 \mathrm{~h}$ : $\mathrm{OR}=1.67,95 \% \mathrm{CI}=1.41-1.98 ;<1 \mathrm{~h}: \mathrm{OR}=2.40,95 \%$ $\mathrm{CI}=1.95-2.96)$ and timing of $\mathrm{ST}(\mathrm{OR}=1.55,95 \% \mathrm{CI}=$ $1.33-1.79)$ were negatively correlated with the academic performance of the participants. These results show that the participants with shorter durations of ST per day showed good performance. In addition, it showed that children who had no ST just before bedtime were more likely to have good performance than those who did.

\section{Combination of the duration and timing of ST}

In this study, we had six combination groups (G1, G2, G3, G4, G5, and G6) (Table 2). We performed logistic

Table 7 Results of logistic regression analysis of ST duration and timing

\begin{tabular}{|c|c|c|c|c|c|c|c|}
\hline & & \multicolumn{2}{|l|}{ Obesity } & \multirow{2}{*}{$\begin{array}{l}\text { Physical activity } \\
\text { Weekly physical activity }\end{array}$} & \multirow{2}{*}{$\begin{array}{l}\text { Dry eyes } \\
\text { Dry eyes }\end{array}$} & \multicolumn{2}{|c|}{ Learning ability } \\
\hline & & BMI percentiles & $\overline{\text { Rohrer index }}$ & & & Class & Performance \\
\hline & & $O R^{a}$ & $\mathrm{OR}^{\mathrm{a}}$ & $O^{a}$ & $O R^{a}$ & $\mathrm{OR}^{\mathrm{a}}$ & $O R^{a}$ \\
\hline & & $95 \% \mathrm{Cl}$ & $95 \% \mathrm{Cl}$ & $95 \% \mathrm{Cl}$ & $95 \% \mathrm{Cl}$ & $95 \% \mathrm{Cl}$ & $95 \% \mathrm{Cl}$ \\
\hline \multirow[t]{5}{*}{ Duration of ST } & Above $3 \mathrm{~h}$ & 1 & 1 & 1 & 1 & 1 & 1 \\
\hline & $1-3 \mathrm{~h}$ & $0.61^{* * * *}$ & $0.65^{* * *}$ & $1.19^{*}$ & 1.15 & $2.24^{* * *}$ & $1.67^{* * *}$ \\
\hline & & $0.50-0.74$ & $0.52-0.81$ & $1.03-1.37$ & $0.97-1.36$ & $1.71-2.94$ & $1.41-1.98$ \\
\hline & Less than $1 \mathrm{~h}$ & $0.42^{* * *}$ & $0.43^{* * *}$ & $1.27^{* *}$ & 1.19 & $3.93^{* * *}$ & $2.4^{* * *}$ \\
\hline & & $0.33-0.54$ & $0.32-0.57$ & $1.08-1.48$ & $0.98-1.45$ & $2.70-5.71$ & $1.95-2.96$ \\
\hline \multirow[t]{2}{*}{ Timing of $S T^{c}$} & No/(Yes) & $0.78^{* *}$ & $0.73^{* *}$ & 1.06 & $1.31^{* * *}$ & $1.43^{* *}$ & $1.55^{* * *}$ \\
\hline & & $0.65-0.93$ & $0.60-0.90$ & $0.95-1.17$ & $1.15-1.50$ & $1.10-1.86$ & $1.33-1.79$ \\
\hline
\end{tabular}

${ }^{* * * *} p<0.001,{ }^{* *} p<0.01,{ }^{*} p<0.05$

a OR odds ratio, $95 \%$ Cl $95 \%$ confidence interval

${ }^{\mathrm{b}}$ The median number of physical activities per week was divided into two

${ }^{c}$ Whether there was ST just before bedtime 
regression analysis to compare G1 and G2, G3 and G4, and G5 and G6 regarding each item. The results are presented in Table 8. For the "BMI percentiles" item, the differences between $\mathrm{G} 4$ and $\mathrm{G} 3(\mathrm{OR}=0.72 ; 95 \% \mathrm{CI}=$ $0.57-0.90)$ was associated with being in the "normal" group. In the "Rohrer index" item, the differences between G4 and G3 (OR = 0.76; 95\% CI $=0.60-0.97)$ was associated with being in the "normal" group. In the "weekly physical activities" item, no predominant association in any combination group was observed. Furthermore, the differences between G4 and G3 (OR = 1.36; $95 \% \mathrm{CI}=1.14-1.63)$ and $\mathrm{G} 6$ and $\mathrm{G} 5(\mathrm{OR}=1.38$; $95 \% \mathrm{CI}=1.08-1.77)$ were associated with "not dry eyes." Regarding the "class" item, no predominant association in any combination group was noted. The differences between $\mathrm{G} 2$ and $\mathrm{G} 1(\mathrm{OR}=1.85 ; 95 \% \mathrm{CI}=1.26-2.72)$, G4 and $\mathrm{G} 3(\mathrm{OR}=1.53 ; 95 \% \mathrm{CI}=1.26-1.85)$ and $\mathrm{G} 6$ and $\mathrm{G} 5$ $(\mathrm{OR}=1.42 ; 95 \% \mathrm{CI}=1.05-1.91)$ were associated with good grades. These results show that the timing of ST had a greater impact on dry eye symptoms, while the duration of ST had a greater effect on academic performance.

\section{Discussion}

\section{Main results}

This study surveyed elementary school children from Minato City to examine the effects of ST duration and timing on obesity, physical activity, dry eyes, and learning ability. The relationships between ST duration and BMI percentile, Rohrer index, weekly physical activity, class, and performance were statistically significant. Furthermore, the relationships between ST timing and BMI percentile, Rohrer index, dry eyes, class, and performance were also statistically significant. In addition, ST timing greatly affected dry eye symptoms, whereas ST duration greatly affected academic performance.
Relationship between ST duration and obesity, physical activity, academic performance, dry eyes

In the present study, children with shorter ST durations were more likely to have normal body weight, higher physical activity, better understanding of the material presented in their classes, and better academic performance.

The relationship between screen media exposure and obesity has been extensively studied. For example, many studies have reported a relationship between watching TV and development of obesity [33-35]. A possible cause for the obesity associated with TV viewing is increased caloric intake while watching TV. Watching TV while eating a meal may increase caloric intake by delaying satiety during meals or by reducing satiety signals from previously consumed food; it may also divert attention from the habitual control of food intake [36]. In addition, longer ST durations are associated with increased sedentary behavior and decreased physical activity, which may be related to obesity. It has been previously reported that children with longer STs have greater obesity and adiposity [37]. Moreover, longer durations of ST, especially due to watching TV, are associated with decreased physical fitness $[3,38]$ and decreased muscle strength, regardless of the physical activity level [39]. Those with longer TV viewing time spend less time in club sports, which may indicate less involvement in overall physical activity [38]. The findings from these studies are consistent with those of our present study that individuals with shorter ST durations spent more time participating in physical activities.

In addition, previous studies have shown that longer ST durations detract from time spent on academic activities such as studying and doing homework [40], and this can cause learning and attention deficits and negative attitudes toward attending school [41]. Another study reported that Japanese children with shorter ST durations were more likely to have high academic performance,

Table 8 Results of the combination of ST duration and timing

\begin{tabular}{|c|c|c|c|c|c|c|}
\hline & $\begin{array}{l}\text { BMI percentiles } \\
\mathrm{OR}^{\mathrm{a}}\end{array}$ & $\begin{array}{l}\text { Rohrer index } \\
O R^{a}\end{array}$ & $\begin{array}{l}\text { Weekly physical activities } \\
{ }^{b}\end{array}$ & $\begin{array}{l}\text { Dry eyes } \\
O R^{a}\end{array}$ & $\begin{array}{l}\text { Class } \\
\mathrm{OR}^{\mathrm{a}}\end{array}$ & $\begin{array}{l}\text { Performance } \\
\mathrm{OR}^{\mathrm{a}}\end{array}$ \\
\hline & $\mathrm{OR}^{\mathrm{a}}$ & $\mathrm{OR}^{\mathrm{a}}$ & $\mathrm{OR}^{\mathrm{a}}$ & $\mathrm{OR}^{\mathrm{a}}$ & & \\
\hline & $95 \% \mathrm{Cl}$ & $95 \% \mathrm{Cl}$ & $95 \% \mathrm{Cl}$ & $95 \% \mathrm{Cl}$ & $95 \% \mathrm{Cl}$ & $95 \% \mathrm{Cl}$ \\
\hline \multirow[t]{2}{*}{$\mathrm{G} 1^{c} \times \mathrm{G} 2^{c}$} & 0.73 & 0.64 & 1.09 & 1.04 & 1.59 & $1.85^{* *}$ \\
\hline & $0.47-1.12$ & $0.40-1.05$ & $0.81-1.48$ & $0.72-1.49$ & $0.88-2.87$ & $1.26-2.72$ \\
\hline \multirow[t]{2}{*}{$\mathrm{G} 3^{\mathrm{C}} \times \mathrm{G} 4^{\mathrm{C}}$} & $0.72^{* *}$ & $0.76^{*}$ & 1.09 & $1.36^{* * *}$ & 1.37 & $1.53^{* * *}$ \\
\hline & $0.57-0.90$ & $0.60-0.97$ & $0.95-1.25$ & $1.14-1.63$ & $0.97-1.93$ & $1.26-1.85$ \\
\hline \multirow[t]{2}{*}{$\mathrm{G} 5^{C} \times G 6^{C}$} & 1.05 & 0.73 & 0.99 & $1.38^{*}$ & 1.41 & $1.42^{*}$ \\
\hline & $0.71-1.56$ & $0.49-1.09$ & $0.81-1.20$ & $1.08-1.77$ & $0.78-2.56$ & $1.05-1.91$ \\
\hline
\end{tabular}

${ }^{* * * *} p<0.001,{ }^{* *} p<0.01,{ }^{*} p<0.05$

${ }^{a} \mathrm{O}$ odds ratio, $95 \% \mathrm{Cl} 95 \%$ confidence interval

${ }^{\mathrm{b}}$ The median number of physical activities per week was divided into two

'Divided into G1 to G6 based on the combination of ST duration and timing (Please refer to Table 2) 
regardless of their physical activity level [42]. In addition, spending on ST for more than $2 \mathrm{~h}$ per day was negatively associated with academic achievement in schoolage children [3]. Taken together, these studies suggest that longer ST durations can influence individual behavioral styles that impinge on academic understanding and performance and contribute to poor grades.

Because the influence of ST through smartphones and tablets is included in this survey, ST other than watching TV may be significantly associated with obesity, physical activity, dry eyes, and academic performance.

\section{Relationship between ST timing and obesity, physical activity, academic performance, dry eyes}

Our results showed that compared to those who had ST, those who did not have ST just before bedtime were more likely to have normal body weight, had no dry eyes, understood the material presented in their classes, and had better academic performance. This may be because late-night ST contributes to evening chronotype behavior [12], and late-night snack consumption is associated with a higher risk of developing obesity and metabolic diseases [43, 44].

As mentioned above, it is believed that ST immediately before bedtime leads to sleep deprivation in children, and studies have reported that sleep deprivation is associated with poor grades [45]. Our results confirmed this hypothesis. Sleep deprivation affects memory retention, increases erroneous memory formation [46], and is associated with lack of judgment and attention [47]. Therefore, sleep deprivation from ST immediately before bedtime could affect attitudes toward learning, learning comprehension, and, ultimately, overall academic achievement.

Moreover, digital device use has been correlated with dry eye symptoms [48] and tear film instability [49]. The interblink interval and tear film instability increase during highly focused work [9-11]. Thus, in the current study, ST immediately before bedtime may be associated with focused ST exposure. Other studies reported that blue light emitted from smart mobile device screens causes eye fatigue $[50,51]$ and that dry eyes are associated with sleep quality [52]. Hence, ST before bedtime can detract from sleep quality and lead to dry eyes.

\section{Influence of the combination of ST duration and ST timing}

Jointly investigating ST duration and timing showed that ST timing had a greater effect than ST duration on dry eye symptoms. Thus, the timing of ST has a significant impact on dry eyes. Currently, we do not know the mechanism behind this, but several possibilities exist. Late-night ST may lead to dry eye symptoms as tear secretion follows the circadian rhythm, with low levels at
21:00 [53]. Further, late-night ST may promote sympathetic activity, and activation of the sympathetic nervous system is known to decrease tear secretion [54]. Another possibility is related to focused nighttime ST exposure, considering that children may be using digital devices without parental supervision at night. Focused ST exposure causes incomplete blinks and tear film instability [9$11]$, and these factors contribute to the risk of dry eyes [55-57]. Regarding academic performance, our study has shown that the ST duration has a greater effect than ST timing, and longer ST durations detract more from academic performance. However, the mechanism of the ST duration and timing effect is not yet clear. Spending more than $2 \mathrm{~h}$ per day in front of the screen was negatively associated with academic achievement among school-age children [3]. Thus, having sufficient study time in the afternoon, early evening, and late evening may be a very important factor in academic achievement. Our results call attention to the different effects of ST dependency (duration and/or timing) on individual areas. Blue light exposure before bedtime causes disturbances of the circadian clock, sleep length, energy metabolism, and academic performance [15]. Among the visible light wavelengths, short wavelengths perceived as blue can strongly affect the phase delay of the circadian rhythm and suppress melatonin [13-15]. Most digital devices emit blue light. Thus, it would be preferable to avoid using digital devices before bedtime, as it could significantly influence sleep quality and the circadian rhythm [15]. Many adolescents exhibit an evening chronotype from exposure to nighttime blue light, and their biological and social rhythms become misaligned. This chronotype can result in sleep disturbances as well as fatigue, daytime sleepiness, behavioral problems, and poor academic achievement, among other negative outcomes [15]. Therefore, parents, school teachers, and leading social media firms should strive to reduce children's late-night ST.

\section{Study strengths and limitations}

In this study, we investigated ST effects on multiple objective variables using the same group of elementary school children. To our knowledge, no studies have examined the effect of the duration and timing of ST on obesity, physical activity, dry eyes, and learning ability in the same group of elementary school children. In addition, by combining the duration and timing of ST, we were able to show not only the effect of ST duration, which has already been discussed in the literature, but also that of ST timing (just before bedtime). The combined analysis of ST duration and timing is a strength of this study.

However, our study has several limitations. First, the surveys failed to reflect the actual lifestyles and 
anthropometric data of the participants. Children may have exaggerated or downplayed aspects of their lifestyles based on social expectations. Second, the study relies on children's answers, which may introduce errors due to their varying interpretations of the questions. Third, because the study focused only on elementary school students, the results may not be applicable to middle school, high school, and college students along with working adults and hence, may not be generalizable. Therefore, it may be necessary to expand the range of participants in future studies. Fourth, the area covered by this study was Minato City, Tokyo, Japan, and it is unclear whether the same results would be obtained in other areas. Therefore, it may be necessary to expand the target area in future studies. Fifth, the results on "dry eyes" obtained in this study are for assessing symptoms, not for diagnosing dry eye. Therefore, it will be necessary to examine them in greater detail using dry eye disease diagnosis indicators. Finally, the validity of the questionnaire used on children in this study has not yet been verified. However, it was created with reference to a questionnaire for adults that has been verified in previous studies; therefore, it is considered that the validity of the result is likely to be guaranteed.

\section{Conclusion}

In conclusion, our study demonstrated that ST immediately before bedtime increases the risk of dry eyes, and longer ST duration can contribute to reduction in academic performance. In addition, our findings indicate that not only the duration but also the timing of ST have important ramifications.

\section{Abbreviations}

ST: Screen time; BMI: Body mass index; WHO: World health organization; HBSC: Behaviour in School-Aged Children; DEQS: Dry Eye-Related Quality-ofLife Score; ORs: Odds ratios; Cis: Confidence intervals; SE: Standard Error

\section{Supplementary Information}

The online version contains supplementary material available at https://doi. org/10.1186/s12889-021-10484-7.

Additional file 1. Questionnaire on the Shokuiku.

\section{Acknowledgements}

Thanks to all participating children and parents involved in the Shokuiku Project.

\section{Authors' contributions}

Y.M., H-K.K., and S.S. designed the research, analyzed the data, and wrote the manuscript. H.C., T.N., T.S., S.F., and S.O. analyzed the data and reviewed the manuscript. M.K. and A.S. reviewed the manuscript. All authors have read and approved the final manuscript.

\section{Funding}

This work was supported by a Grant-in-Aid for Scientific Research (A) $19 H 01089$ and Grant-in-Aid for challenging Exploratory Research 19 K21597 from the Japan Society for the Promotion of Science (S.S). The funders had no role in the design of study and collection, analysis, the decision to publish, or preparation of the manuscript.

Availability of data and materials

The datasets for the current study are available from the corresponding author on reasonable request.

\section{Declarations}

Ethics approval and consent to participate

Prior to the study, the written informed consent of a parent or guardian was obtained for participants under 16 years old after delivering a detailed description of the study (i.e. purpose, methods). This study's protocol conformed to the Helsinki Declaration and was approved by the Ethics Review Committee on Research with Human Subjects of Waseda University, Tokyo, Japan (application no. 2019-195).

Consent for publication

Not applicable.

\section{Competing interests}

We declare that there are no conflicts of interest related to this study.

Received: 23 September 2020 Accepted: 22 February 2021

Published online: 28 February 2021

\section{References}

1. Survey of parents' awareness of children with smartphones for the first time this year. Available online: https://mmdlabo.jp/investigation/detail_1838. html (accessed on 4 July 2020).

2. Survey on Internet usage environment of young people in 2018. Available online: https://www8.cao.go.jp/youth/youth-harm/chousa/h30/net-jittai/pdf/ sokuhou.pdf (accessed on 4 July 2020).

3. Tremblay MS, LeBlanc AG, Janssen I, Kho ME, Hicks A, Murumets K, Colley RC, Duggan M. Canadian sedentary behaviour guidelines for children and youth. Appl Physiol Nutr Metab. 2011;36:59-64. https://doi.org/10.1139/H11012.

4. World Health Organization. Global Recommendations on Physical Activity for Health. 2010. Available online: http://whqlibdoc.who.int/publications/201 0/9789241599979_eng.pdf (accessed on 4 July 2020).

5. Ishii K, Shibata A, Adachi M, Mano Y, Oka K. School grade and sex differences in domain-specific sedentary behaviors among Japanese elementary school children: a cross-sectional study. BMC Public Health. 2017;17:318. https://doi.org/10.1186/s12889-017-4221-z.

6. Ishii K, Shibata A, Adachi M, Nonoue K, Oka K. Gender and grade differences in objectively measured physical activity and sedentary behavior patterns among Japanese children and adolescents: across-sectional study. BMC Public Health. 2015;15:1254. https://doi.org/10.1186/s12889-015-2607-3.

7. Marques A, Santos DA, Hillman CH, Sardinha LB. How does academic achievement relate to cardiorespiratory fitness.; self-reported physical activity and objectively reported physical activity: A systematic review in children and adolescents aged 6-18 years. Br J Sports Med. 2018;52(16): 1039. https://doi.org/10.1136/bjsports-2016-097361.

8. Adelantado-Renau M, Moliner-Urdiales D, Cavero-Redondo I, Beltran-Valls MR, Martínez-Vizcaíno V, Álvarez-Bueno C. Association between screen media use and academic performance among children and adolescents: a systematic review and meta-analysis. JAMA Pediatr. 2019;173(11):1058-76. https://doi.org/10.1001/jamapediatrics.2019.3176.

9. Bron AJ, Tomlinson A, Foulks GN, Pepose JS, Baudouin C, Geerling G, Nichols KK, Lemp MA. Rethinking dry eye disease: a perspective on clinical implications. Ocul Surf. 2014;12(2 Suppl):S1-31. https://doi.org/10.1016/j. jtos.2014.02.002.

10. Cardona G, Garcia C, Seres C, Vilaseca M, Gispets J. Blink rate, blink amplitude, and tear film integrity during dynamic visual display terminal tasks. Curr Eye Res. 2011;36(3):190-7. https://doi.org/10.3109/02713683.2010. 544442

11. Himebaugh NL, Begley CG, Bradley A, Wilkinson JA. Blinking and tear breakup during four visual tasks. Optom Vis Sci. 2009:86(2):E106-14. https:// doi.org/10.1097/OPX.0b013e318194e962. 
12. Shibata S, Tahara Y, Hirao A. The adjustment and manipulation of biological rhythms by light, nutrition, and abused drugs. Adv Drug Deliv Rev. 2010; 62(9-10):918-27. https://doi.org/10.1016/j.addr.2010.06.003.

13. Wahl S, Engelhardt M, Schaupp P, Lappe C, Ivanov IV. The inner clock-blue light sets the human rhythm. J Biophotonics. 2019;12(12):e201900102. https://doi.org/10.1002/jbio.201900102.

14. Tähkämö L, Partonen T, Pesonen AK. Systematic review of light exposure impact on human circadian rhythm. Chronobiol Int. 2019;36(2):151-70. https://doi.org/10.1080/07420528.2018.1527773.

15. Touitou Y, Touitou D, Reinberg A. Disruption of adolescents' circadian clock: The vicious circle of media use, exposure to light at night, sleep loss and risk behaviors. J Physiol Paris. 2016;110(4 Pt B):467-79. https://doi.org/10.101 6/j.jphysparis.2017.05.001.

16. Dietz WH, Robinson TN. Use of the body mass index (BMI) as a measure of overweight in children and adolescents. J Pediatr. 1998;132(2):191-3. https:// doi.org/10.1016/s0022-3476(98)70426-3.

17. Rolland-Cachera MF, Sempé M, Guilloud-Bataille $M$, Patois E, PéquignotGuggenbuhl F, Fautrad V. Adiposity indices in children. Am J Clin Nutr. 1982;36(1):178-84. https://doi.org/10.1093/ajcn/36.1.178.

18. Ministry of Health, Labor and Welfare. About the present condition of height and weight of infants. Available online: https://www.mhlw.go.jp/seisa kunitsuite/bunya/kodomo/kodomo_kosodate/boshi-hoken/kenkou-02.html (accessed on 8 September 2020).

19. Ohnishi M, Leshabari S, Ambikile JS, Oishi K, Nakao Y, Nishihara M. Associations among anthropometric measures, food consumption, and quality of life in school-age children in Tanzania. J Rural Med. 2017;12(1):3845. https://doi.org/10.2185/jrm.2924.

20. Hallal PC, Andersen LB, Bull FC, Guthold R, Haskell W, Ekelund U. Lancet physical activity series working group. Global physical activity levels: surveillance progress, pitfalls, and prospects. Lancet. 2012;380(9838):247-57. https://doi.org/10.1016/S0140-6736(12)60646-1.

21. Kohl HW, Fulton JE, Casperson CJ. Assessment of physical activity among children and adolescents: a review and synthesis. Prev Med. 2000;31:S54-76.

22. World Health Organization Available online: https://www.euro.who.int/en/ health-topics/Life-stages/child-and-adolescent-health/health-behaviour-inschool-aged-children-hbsc/about-hbsc (accessed 8 September 2020).

23. Tanaka C, Kyan A, Takakura M, Olds T. The validity of the Japanese version of physical activity questions in the WHO health behaviour in school-aged children (HBSC) survey. Res Exerc Epidemiol. 2017;19(2):93-101.

24. Sakane $Y$, Yamaguchi M, Yokoi N, Uchino M, Dogru M, Oishi T, Ohashi Y, Ohashi Y. Development and validation of the dry eye-related quality-of-life score questionnaire. JAMA Ophthalmol. 2013;131(10):1331-8. https://doi. org/10.1001/jamaophthalmol.2013.4503.

25. Yamada M, Sekine M, Tatsuse T, Asaka Y. Association between lifestyle, parental smoke, socioeconomic status, and academic performance in Japanese elementary school children: the super diet education project. Environ Health Prev Med. 2019;24(1):22. https://doi.org/10.1186/s12199019-0776-x.

26. Kohyama J. Self-reported academic performance and lifestyle habits of school children in Japan. Int J Child Health Nutr. 2017;6:90-7.

27. Stroebele N, McNally J, Plog A, Siegfried S, Hill JO. The association of selfreported sleep, weight status, and academic performance in fifth-grade students. J Sch Health. 2013;83(2):77-84. https://doi.org/10.1111/josh.12001.

28. Kuncel NR, Crede M, Thomas LL. The validity of self-reported grade point average, class ranks, and test score: a meta-analysis and review of the literature. Rev Educ Res. 2005;75:62-82.

29. Council on communications and media. Children, adolescents, and the media. Pediatrics. 2013;132(5):958-61. https://doi.org/10.1542/ peds.2013-2656.

30. Council on Communications and Media, Brown A. Media use by children younger than 2 years. Pediatrics. 2011;128(5):1040-5. https://doi.org/10.1 542/peds.2011-1753.

31. Minato-ku Board of Education. Minato-ku School Informatization Action Plan Available online: https://www.city.minato.tokyo.jp/kyouikushomu/kodomo/ gakko/documents/actionplan30-32.pdf (accessed 8 September 2020).

32. Domingues-Montanari S. Clinical and psychological effects of excessive screen time on children. J Paediatr Child Health. 2017;53(4):333-8. https:// doi.org/10.1111/.jpc.13462.

33. Viner RM, Tim J. Television viewing in early childhood predicts adult body mass index. Pediatrics. 2005;147(4):429-35. https://doi.org/10.1016/j.jpeds.2 005.05 .005 .
34. Hancox RJ, Milne BJ, Poulton R. Association between child and adolescent television viewing and adult health: a longitudinal birth cohort study. Lancet. 2004;364(9430):257-62. https://doi.org/10.1016/ S0140-6736(04)16675-0.

35. Carson V, Hunter S, Kuzik N, Gray CE, Poitras VJ, Chaput J-P, Saunders TJ, Katzmarzyk PT, Okely AD, Gorber SC, Kjo ME, Sampson M, Lee H, Tremblay MS. Systematic review of sedentary behaviour and health indicators in school-aged children and youth: an update. Appl Physiol Nutr Metab. 2016; 41(6):240-65. https://doi.org/10.1139/apnm-2015-0630.

36. Bellissimo N, Pencharz PB, Thomas SG, Anderson GH. Effect of television viewing at mealtime on food intake after a glucose preload in boys. Pediatr Res. 2007;61:745-9. https://doi.org/10.1203/pdr.0b013e3180536591.

37. Stiglic N, Viner RM. Effects of screentime on the health and well-being of children and adolescents: a systematic review of reviews. BMJ Open. 2019; 9(1):e023191. https://doi.org/10.1136/bmjopen-2018-023191.

38. Greier K, Drenowatz C, Ruedl G, Riechelmann H. Association between daily TV time and physical fitness in 6- to 14-year-old Austrian youth. Transl Pediatr. 2019;8(5):371-7. https://doi.org/10.21037/2Ftp.2019.03.03.

39. Paalanne NP, Korpelainen RI, Taimela SP, Auvinen JP, Tammelin TH, Hietikko TM, Kaikkonen HS, Kaikkonen KM, Karppinen Jl. Muscular fitness in relation to physical activity and television viewing among young adults. Med Sci Sports Exerc. 2009;41(11):1997-2002. https://doi.org/1 0.1249/MSS.0b013e3181a7f3a6.

40. Vandewater EA, Bickham DS, Lee JH. Time well spent? Relating television use to children's free-time activities. Pediatrics. 2006;117(2):181-91. https:// doi.org/10.1542/peds.2005-0812.

41. Johnson JG, Cohen P, Kasen S, Brook JS. Extensive television viewing and the development of attention and learning difficulties during adolescence. Arch Pediatr Adolesc Med. 2007;161(5):480-6. https://doi.org/10.1001/a rchpedi.161.5.480.

42. Ishii K, Aoyagi K, Shibata A, Koohsari MJ, Carver A, Oka K. Joint associations of leisure screen time and physical activity with academic performance in a sample of Japanese children. Int J Environ Res Public Health. 2020;17(3):757. https://doi.org/10.3390/ijerph17030757.

43. Lopez-Minguez J, Gómez-Abellán P, Garaulet M. Timing of Breakfast, Lunch, and Dinner. Effects on Obesity and Metabolic Risk. Nutrients. 2019;11(11): 2624. https://doi.org/10.3390/nu11112624.

44. Rešetar J, Pfeifer D, Mišigoj-Duraković M, Sorić M, Kljusurić JG, Šatalić Z. Eveningness in energy intake among adolescents with implication on anthropometric indicators of nutritional status: the CRO-PALS longitudinal study. Nutrients. 2020;12(6):1710. https://doi.org/10.3390/nu12061710.

45. Schmidt RE, Van der Linden M. The relations between sleep, personality, behavioral problems, and school performance in adolescents. Sleep Med Clin. 2015;10(2):117-23. https://doi.org/10.1016/j.jsmc.2015.02.007.

46. Lo JC, Chong PL, Ganesan S, Leong RL, Chee MW. Sleep deprivation increases formation of false memory. J Sleep Res. 2016;25(6):673-82. https:// doi.org/10.1111/jsr.12436.

47. Harrison $Y$, Horne JA. The impact of sleep deprivation on decision making: a review. J Exp Psychol Appl. 2000;6(3):236-49. https://doi.org/10.1037//1076$898 \times 6.3 .236$.

48. Uchino M, Schaumberg DA, Dogru M, Uchino Y, Fukagawa K, Shimmura S, Satoh T, Takebayashi T, Tsubota K. Prevalence of dry eye disease among Japanese visual display terminal users. Ophthalmology. 2008;115(11):1982-8. https://doi.org/10.1016/j.ophtha.2008.06.022.

49. Uchino M, Yokoi N, Uchino Y, Dogru M, Kawashima M, Komuro A, Sonomura Y, Kato H, Kinoshita S, Schaumberg DA, Tsubota K. Prevalence of dry eye disease and its risk factors in visual display terminal users: the Osaka study. Am J Ophthalmol. 2013;156(4):759-66. https://doi.org/10.1016/j.ajo.2 013.05.040.

50. Kim DJ, Lim CY, Gu N, Park CY. Visual fatigue induced by viewing a tablet computer with a high-resolution display. Korean J Ophthalmol. 2017;31(5): 388-93. https://doi.org/10.3341/kjo.2016.0095.

51. Tosini G, Ferguson I, Tsubota K. Effects of blue light on the circadian system and eye physiology. Mol Vis. 2016;22:61-72.

52. Oh JH, Yoo H, Park HK, Do YR. Analysis of circadian properties and healthy levels of blue light from smartphones at night. Sci Rep. 2015;5:11325. https://doi.org/10.1038/srep11325.

53. Srinivasan $\mathrm{S}$, Chan $\mathrm{C}$, Jones L. Apparent time-dependent differences in inferior tear meniscus height in human subjects with mild dry eye symptoms. Clin Exp Optom. 2007;90(5):345-50. https://doi.org/10.1111/ j.1444-0938.2007.00174.x. 
54. Nakamura S, Kinoshita S, Yokoi N, Ogawa Y, Shibuya M, Nakashima H, Hisamura R, Imada T, Imagawa T, Uehara M, Shibuya I, Dogru M, Ward S,

Tsubota K. Lacrimal hypofunction as a new mechanism of dry eye in visual display terminal users. PLoS One. 2010;5(6):e11119. https://doi.org/10.1371/ journal.pone.0011119.

55. Pult $\mathrm{H}$, Riede-Pult $\mathrm{BH}$, Murphy PJ. The relation between blinking and conjunctival folds and dry eye symptoms. Optom Vis Sci. 2013;90(10):1034-9. https://doi.org/10.1097/OPX.0000000000000029.

56. Craig JP, Nichols KK, Akpek EK, Caffery B, Dua HS, Joo C-K, Liu Z, Nelson JD, Nichols JJ, Tsubota K, Stapleton F. TFOS DEWS II definition and classification report. Ocul Surf. 2017;15(3):276-83. https://doi.org/1 0.1016/j.jtos.2017.05.008

57. Wolkoff P, Nojgaard JK, Troiano P, Piccoli B. Eye complaints in the office environment: precorneal tear film integrity influenced by eye blinking efficiency. Occup Environ Med. 2005;62(1):4-12. https://doi.org/10.1136/ oem.2004.016030

\section{Publisher's Note}

Springer Nature remains neutral with regard to jurisdictional claims in published maps and institutional affiliations.

Ready to submit your research? Choose BMC and benefit from:

- fast, convenient online submission

- thorough peer review by experienced researchers in your field

- rapid publication on acceptance

- support for research data, including large and complex data types

- gold Open Access which fosters wider collaboration and increased citations

- maximum visibility for your research: over $100 \mathrm{M}$ website views per year

At $\mathrm{BMC}$, research is always in progress.

Learn more biomedcentral.com/submissions 